\title{
Concepção e montagem de uma exposição arqueológica de curta duração no Museu das Culturas Dom Bosco - MCDB
}

\author{
Dirceu Mauricio van Lonkhuijzen *
}

\begin{abstract}
VAN LONKHUIJZEN, D.M. Concepção e montagem de uma exposição arqueológica de curta duração no Museu das Culturas Dom Bosco - MCDB. Revista do Museu de Arqueologia e Etnologia, São Paulo, 18: 307-313, 2008.
\end{abstract}

Resumo: Esta comunicação apresenta a síntese do desenvolvimento da montagem de uma exposição arqueológica de curta duração, tendo como objetivo, atender provisoriamente a demanda de público visitante ao Museu das Culturas Dom Bosco - MCDB. Este trabalho integrou uma proposta alternativa a fim de compensar a ausência de comunicação museal completa neste período. Os resultados obtidos permitiram a visualização da necessidade da utilização da comunicação gráfica geral e de detalhes, visando-se a ampliar a correlação da forma com o objeto e conteúdo com a informação de uma exposição arqueológica.

Palavras-chave: Museologia - Educação - Comunicação.

\section{Introdução}

$\mathrm{N}$ os últimos anos, os museus conquistaram espaço em todo o mundo como instituições de vanguarda, principalmente, na educação para a preservação do patrimônio artístico, cultural, científico e tecnológico (Gaspar 1993). No Brasil, este modelo de museu moderno que apresenta uma nova postura voltada para o social, tendo a educação não formal como grande aliada na desmistificação de que "museu é local de coisas velhas" ainda está engatinhando, com alguns exemplos conhecidos nos museus das regiões Sul e Sudeste do país. Segundo Cury (2005a), os museus não podem mais ser conceituados como depósitos e sim

${ }^{*}$ ) Museu das Culturas Dom Bosco - MCDB. Geógrafo, técnico responsável pela coleção de arqueologia.dirceu@ucdb.br como museus que pensam no sentido das coisas do mundo e na vida, re-elaborando constantemente sua missão poética.

Hoje, os museus brasileiros vivem um momento de reinvenção, como é o caso do Museu das Culturas Dom Bosco - MCDB, localizado na cidade de Campo Grande, capital do Mato Grosso do Sul. Caracterizado por uma nova proposta museológica, a instituição deixa de ser apenas um local de depósito passivo ou simples expositor de objetos que representam o patrimônio natural e cultural, para tornar-se um local de descobertas científicas, transformando-se em instituição dinâmica, ativa na construção da cultura, educação e na pesquisa, em destaque, por ser um museu Universitário, ligado à Universidade Católica Dom Bosco - UCDB.

No ano de 2005, o Museu que se denominava Museu Dom Bosco - MDB muda de nome e de lugar. Seu nome passa a ser Museu das Culturas Dom Bosco - MCDB e assim começa 
Concepção e montagem de uma exposição arqueológica de curta duração no Museu das Culturas Dom Bosco - MCDB. Revista do Museu de Arqueologia e Etnologia, São Paulo, 18: 307-313, 2008.

um minucioso processo de transferência de seu rico acervo, constituído por coleções de mineralogia, etnologia, zoologia, paleontologia e de arqueologia.

A transferência do referido acervo foi efetuada para um novo espaço, ainda em construção, localizado no parque urbano denominado Parque das Nações Indígenas, próximo ao centro da cidade e do antigo prédio do Museu Dom Bosco - MDB.

Durante o processo de transferência foram realizados os procedimentos de desmontagem da exposição do MDB e sua devida documentação por meio de registro fotográfico, e da realização de inventário, higienização das peças e acondicionamentos para transporte e armazenamento. Este trabalho foi importante para a fundamentação teórica e exercício das práticas museais, preparando a equipe técnica do museu para as fases de concepção e montagem de exposições em um novo espaço, dando seqüência assim ao processo de transferência do seu acervo.

No dia trinta de novembro de 2006 foi realizada a inauguração de parte das estruturas de instalação do novo Museu das Culturas Dom Bosco - MCDB. Com isto, surge a necessidade da montagem da exposição de curta duração das coleções etnológica e arqueológica.

A coleção arqueológica foi selecionada para descrever as atividades experimentais de educação patrimonial arqueológica com o público visitante, pois já havia alguns trabalhos desenvolvidos pelo técnico responsável pelo setor neste sentido e pelo fato de esta coleção possuir alguns objetos didáticos que possibilitam o toque.

O presente trabalho consiste em apresentar a produção de uma exposição com o título "Arqueologia Brasileira", cujo objetivo foi divulgar os conhecimentos sobre a pré-história brasileira para os visitantes do museu, durante o período em que esteve aberto entre os dias $30 \mathrm{de}$ novembro de 2006 a 10 de agosto de 2007. Visando proporcionar aos convidados do evento de inauguração e posteriormente, às vinte duas instituições de ensino que recebemos durante este período de visitação, o conhecimento e a valorização da pré-história do Brasil e de Mato Grosso do Sul.

\section{A comunicação museográfica do MCDB}

A necessidade de ações voltadas à popularização da ciência e cultura tem sido percebida como essencial evidenciando para a sociedade a contribuição social, cultural e econômica da atividade científica (Rocha et al. 2003). No caso das instituições salesianas de ensino, essas ações sociais são baseadas na proximidade e na felicidade conforme a carta de Roma escrita por Dom Bosco. Para Dom Bosco não há tempo em que se toma a posição de educador e tempo em que o salesiano não seja um educador (Castro 2007).

Considerando que a dimensão educativa sempre esteve presente no sistema de ensino salesiano programado pela Missão Salesiana do Mato Grosso - MSMT e de pesquisa e extensão da Universidade Católica Dom Bosco - UCDB, da qual o Museu das Culturas Dom Bosco MCDB faz parte, historicamente, Dom Bosco tem uma forte ligação com projetos e ações de educação e que hoje passaram a ser implantados em conformidade com as diretrizes museológicas do $\mathrm{MCDB}$, recorrendo às atividades práticas, interdisciplinares, baseadas na cooperação e na participação, buscando estabelecer relação entre a sensibilização para o meio ambiente e pela diversidade cultural, com a aquisição de conhecimentos, habilidades e atitudes, que visam à elucidação de valores em uma perspectiva crítica e reflexiva.

Neste sentindo, o MCDB que durante a fase de acomodação a um novo espaço, ainda em formação e que também carece de componentes de estrutura museal, exige a busca de estratégias que apontem para diferentes caminhos e possibilidades de discursos expositivos. Com isso, o Museu realizou uma experiência expositiva em que a comunicação gráfica museal não esteve presente, e para diminuir esta falta de informação foram criadas soluções alternativas.

Segundo Lord e Lord (1998) "estratégia museográfica” refere-se ao modelo de apresentação ou ao modo como o museu utiliza a "exposição” como meio para a comunicação com o público, podendo apresentar-se em seis modelos predominantes, que de acordo com os autores, seriam o contemplativo, o temático, o ambiental, o classificatório, o interativo e o experimental. 
Nesta experiência expositiva foi possível adaptar o modelo interativo apresentado por Lord e Lord (1998) para a exposição arqueológica de curta duração "Arqueologia Brasileira"; motivando o visitante a estabelecer um diálogo com a exposição sem comunicação gráfica, apoiando-se na forma estética da exposição, como também, em informações através de palestras e visitas pré-agendadas, acompanhadas por monitores e técnicos do MCDB. Foi importante ressaltar também, informações destinadas aos visitantes para evitarmos situações de risco e de má conduta durante a visita ao $\mathrm{MCDB}$, estimulando, ainda, reflexões diante da importância de se conhecer a Pré-história do Brasil.

\section{A exposição provisória de curta duração "Arqueologia Brasileira"}

Conforme Cury (2005a), a exposição é, didaticamente falando, conteúdo e forma, sendo que o conteúdo é dado pela informação científica e comunicação museal. A forma da exposição diz respeito à maneira como vamos organizá-la, considerando seu tema, a seleção de objetos e a elaboração de outras estratégias que juntas revestem a exposição.

Na exposição provisória do MCDB "Arqueologia Brasileira”, desenvolvida pela equipe técnica do Museu das Culturas Dom Bosco, utilizou-se de uma metodologia expositiva experimental, na qual foram combinados diferentes modelos com ênfase nos recursos estéticos da comunicação visual, na valorização da percepção por meio da contemplação.

Sabe-se que os recursos expográficos variam dos mais simples aos mais sofisticados que se utilizam de tecnologia avançada. Desde textos, legendas, ilustrações, fotografias, mobiliário, cenários, cheiros, sons, imagens e até temperatura similar ao ambiente real, compõem um conjunto de elementos enriquecedores da experiência do público, na medida em que se potencializa a interação entre público e o que esta sendo exposto (Silverstone 1994).

Hoje a tecnologia rege a composição dessas opções comunicativas e quando falo de tecnologias, me refiro a tecnologias de produção de bens de consumo, refiro-me a projeções de vídeos, computadores ligados em redes comunicacionais. Para falarmos dessas tecnologias em nosso cotidiano é preciso que seja feita uma reflexão filosófica sobre a nova condição antropológica e, conseqüentemente, sobre as novas formas e padrões da estética instaurada pelas tecnologias comunicacionais, bem como sobre o destino reservado, nessa nossa situação, às categorias estéticas tradicionais (forma, beleza, sublime, obra, gênio) (Costa 1988: 18, apud Fabris 1995: 7).

É vital para o futuro preocupar-se com a racionalização na obtenção da informação. Informação e decisão serão condições cada vez mais importantes para a inserção na competitividade que caracteriza o mundo de hoje, mas também para a preservação da memória e resgate da cidadania (Souza 2000, apud Ribeiro 2000, V: 250).

A exposição "Arqueologia Brasileira" não utilizou da apresentação de textos relacionados aos objetos da exposição, como no caso dos painéis informativos, pelo fato de o MCDB passar por um momento de acomodação ao seu novo espaço. Sendo assim, foi elaborada uma estratégia com objetivo de compensar esta falta de comunicação gráfica por meio de uma comunicação oral em palestras e durante a condução pelo espaço expositivo dos visitantes junto aos técnicos e monitores que trabalham no Museu e também através do estimulo à percepção dos visitantes das formas metaforizadas da exposição (Fig. 1).

Quanto ao modelo expositivo desta exposição provisória de arqueologia, abrangeu os seguintes temas: Conhecimento e caracterização do período arcaico ${ }^{1}$ e formativo, ${ }^{2}$ questões de uso dos objetos relacionados à sua utilidade contemporânea. Para isso a linguagem utilizada objetivou aproximar as diferentes formas (utilitárias ou simbólicas) de apropriação dos objetos arqueológicos em uma perspectiva integrada, enfatizando a noção de tempo e espaço. Assim, optou-se por um roteiro que

(1) Período marcado pelos povos caçadores coletores.

(2) Período marcado pelos povos agricultores ceramistas. 
Concepção e montagem de uma exposição arqueológica de curta duração no Museu das Culturas Dom Bosco - MCDB. Revista do Museu de Arqueologia e Etnologia, São Paulo, 18: 307-313, 2008.

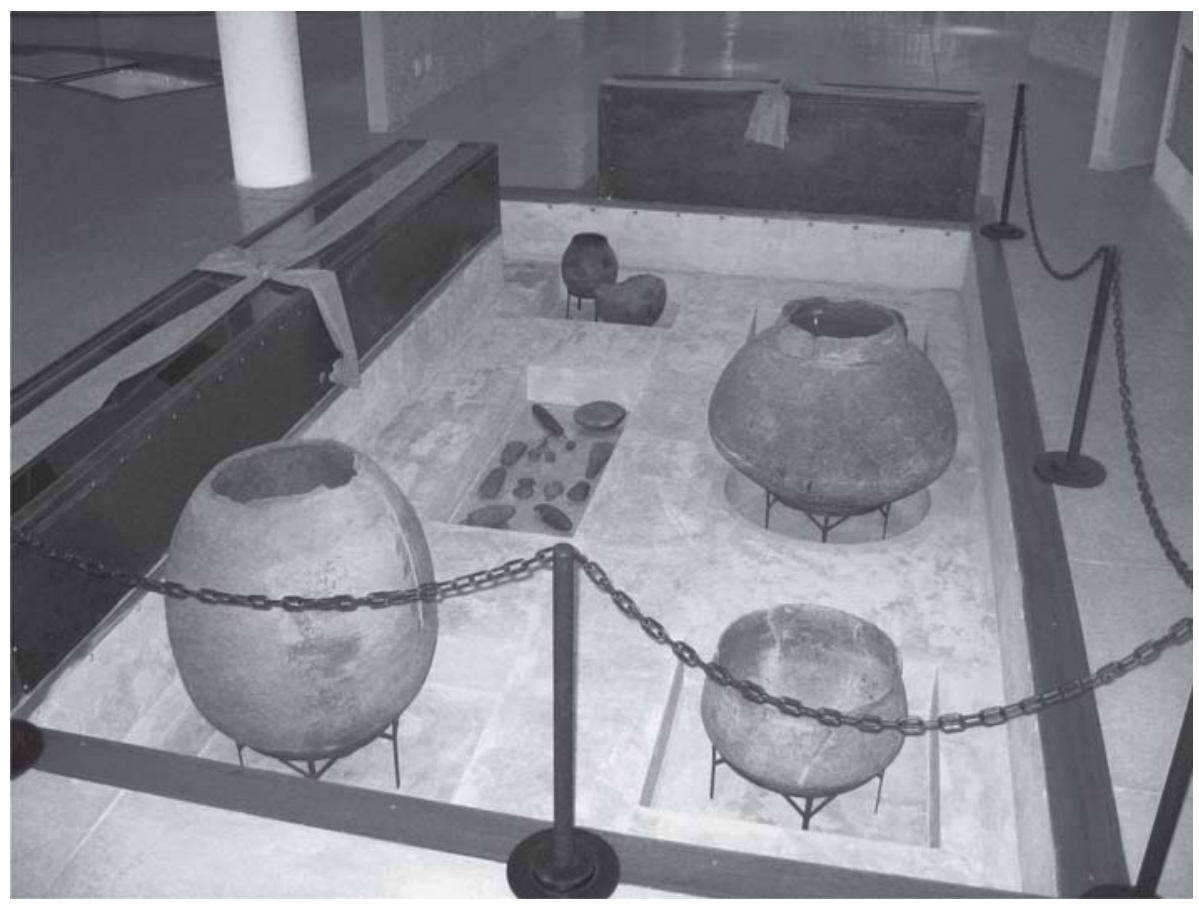

Fig. 1. Exposição provisória de arqueologia brasileira do MCDB.

preparou o visitante para diferentes manifestações e práticas agrupadas pelas idéias de coletar, caçar, plantar, colher, transformar e celebrar, que enfatizam a noção de processo e constituem o eixo ou "pano de fundo" da exposição.

Tendo em vista a amplitude do tema e a situação por que o MCDB passa, a exposição foi tratada como atividade experimental, assumindo seu caráter declaradamente provisório e parcialmente aberta ao público. A exposição de curta duração de arqueologia ocupou um espaço de aproximadamente $9 \mathrm{~m}^{2}$ que durante este período expositivo representou metaforicamente uma escavação arqueológica e não contou com o auxilio comunicativo dos painéis gráficos informativos, monitores de consulta digital ou mesmo projeções no espaço expositivo, pois como, citado anteriormente, o MCDB passava por uma fase de instalação e montagem.

Segundo Lakoff e Turner (1989), a metáfora é uma figura de linguagem que compara seletivamente destacando as qualidades de um sujeito consideradas importantes para aquele que a usa. Para estes autores, a metáfora é uma ponte que liga domínios semânticos diferentes fazendo, assim, com que percebamos novos caminhos para a compreensão do sujeito. A metáfora é uma maneira de expandir os significados de palavras além do literal ao abstrato e uma maneira de expressar o pensamento abstrato em termos simbólicos.

Pollio et al. (1990), comentam que o processo de construção da metáfora parece se dar na tentativa de fazer o mundo abstrato compreensível ou em trazer o mundo para dentro de nós mesmos ou de irmos até ele. Cacciari (1998) diz que o ser humano ao pensar em proferir uma sentença, tem a sua disposição várias escolhas entre elas a de que forma deseja se expressar: literalmente, ironicamente, metaforicamente entre outras. Entretanto, muito pouco é conhecido sobre o que leva o sujeito a escolher o registro preferido. Assim sendo, a metáfora lingüística desempenha um papel importantíssimo no nosso discurso diário e no processo de formação do nosso pensamento (Lakoff 1987 e Turner 1996, apud Cacciari 1998: 120). 
A função da metáfora no caso da exposição provisória do MCDB é, assim, a de estender as capacidades de comunicação e conceitualização do visitante para com a exposição. Segundo Cacciari (1998), a metáfora é uma "janela" para os sistemas do conhecimento que são relevantes e centrais em uma determinada cultura.

Nesta exposição provisória de Arqueologia a comunicação foi realizada através de multimídia onde passamos informações gerais. Combinando imagens à forma da exposição, metaforizando uma escavação, dos objetos expostos e informações possíveis a oferecer ao público visitante, meios de conhecer e discutir as idéias e ações da préhistória brasileira. O público alvo foi formado de maneira geral por alunos e professores do ensino fundamental e médio do município de Campo Grande. A atividade de visitação à exposição "Arqueologia Brasileira" do Museu iniciava-se com a chegada dos grupos de visitantes ao anfiteatro do MCDB para assistirem a uma breve apresentação com temas de educação patrimonial, abordando questões de regras dentro do espaço expositivo e conceitos museológicos, além de informações sobre as particularidades das coleções arqueológicas e etnográficas.

No caso dos objetos da coleção arqueológica, foram selecionadas 13 peças líticas ${ }^{3}$ e 13 de peças de cerâmica, totalizando 26 objetos que se encontravam expostos na parte interna do espaço destinado a esta coleção.

Quanto à descrição e tipologias dos objetos selecionados podemos classificar os objetos líticos como: percutores, raspadores, cortadores, furadores e uma boleadeira de três pontas. Nos objetos de cerâmica selecionamos objetos sem decoração externa, tais como: potes e vasilhas de diferentes tamanhos e duas grandes urnas funerárias.

A exposição apresentou-se neste momento mais próxima do público visitante, pois os objetos expostos não possuíam a proteção de

(3) Objetos como instrumentos ou adornos feitos de pedra. vitrine. Isso ofereceu uma melhor visualização, além do estímulo à curiosidade. A vontade de tocá-las por parte dos visitantes era grande, porém o toque nas peças não era permitido, como foi explicado em apresentação prévia de palestra informativa e durante a visita à exposição provisória de curta duração "Arqueologia Brasileira".

Parte das vitrines da exposição, mais precisamente as vitrines laterais que possuem proteção de vidro permaneceram vazias durante o período em que a exposição esteve aberta e também não apresentaram comunicação gráfica, pois a pesquisa referente ao conteúdo informativo relativo à exposição de maneira geral, tais como, textos e imagens estão sendo elaborados juntamente com o processo de abastecimento de informações do banco de dados digital do arquivo histórico do MCDB.

\section{Conclusões}

Os museus são instituições aparelhadas para atuar como pontes entre culturas e as reflexões que levam a essa concepção, devem levar o público de museu para um campo de valorização da diversidade e para exercitar a diferença como proposta para uma cidadania planetária de respeito (Cury 2005b).

Neste sentido o Museu das Culturas Dom Bosco, em sua longa história, vem cumprindo seu papel de espaço, adequado à educação e formação de cidadania, estimulando vocações científicas e, sobretudo, contribuindo para a expansão de uma consciência crítica e o exercício pleno desta cidadania.

Concluímos com este trabalho que objetivou satisfazer uma demanda de público limitado a um curto período de abertura da exposição provisória "Arqueologia Brasileira", que alcançou suas expectativas quanto ao estímulo e reflexão de conteúdos da préhistória brasileira de forma parcial, isto porque ficou clara para a equipe técnica do MCDB, durante as experiências com palestras e acompanhamento dos grupos de visitantes, a importância da comunicação gráfica para que este conjunto de recursos expográficos seja 
eficiente e cumpra seu papel na comunicação museal (Silverstone 1994).

Por outro lado, a experiência adquirida com as atividades de palestra e visita ao acervo arqueológico exposto, inserido em uma proposta metafórica de sítio arqueológico, sem comunicação gráfica, possibilitou também o despertar da curiosidade do público visitante relativo aos objetos expostos, estimulando, também, o exercício mental de associação do que foi dito em palestra com as formas e o objeto exposto durante a visita monitorada.

Quanto às formas e conteúdos da exposição, notou-se que, pelo fato de o material exposto selecionado apresentar diferentes formas e tamanhos, isto determinava como eram percebidos pelo público visitante. Foi evidente também que o conteúdo oral é problemático, já que se pode perceber por meio de observações realizadas durante as visitas monitoradas pela equipe técnica do $\mathrm{MCDB}$ que nem todos monitores conseguiam se manter fiéis às principais características destacadas pelo responsável do setor sobre um determinado objeto, e isso refletia de maneira direta na compreensão do visitante e na divulgação do conhecimento, comprometendo o alcance dos objetivos propostos.

Portanto, consideramos que nesta experiência de exposição provisória, mesmo com o destaque dado às formas, tendo uma voz própria, a falta de comunicação gráfica dificultou o entendimento do visitante, trazendo-lhe dúvidas quanto ao conteúdo informativo que a exposição "Arqueologia Brasileira" buscava passar, quanto à pré-história brasileira, durante o período em que esteve aberta.

\section{Agradecimentos}

À equipe do Museu das Culturas Dom Bosco - MCDB, em especial para Dra. Dulcilía Lucia de Oliveira Silva e Dra. Aivone Carvalho Brandão.

Apoio:

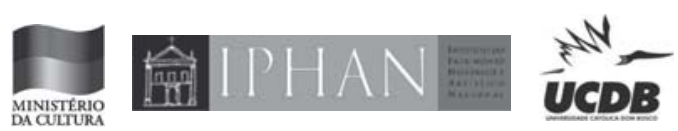

VAN LONKHUIJZEN, D.M. The conception and assembly of an archaeological exhibition of short standing at the Museu das Culturas Dom Bosco - MCDB. Revista do Museu de Arqueologia e Etnologia, São Paulo, 18: 307-313, 2008.

\begin{abstract}
This communication presents the synthesis of the development of an archaeological collection of short standing, having as objective, to meet provisionally the demand of public visitors to the Museu das Culturas Dom Bosco - MCDB. This work integrated an alternative suggestion with the objective to compensate the absence of museal completed communication in this time. The results permitted the viewing of the necessity of a complete museal communication (graphic and technological), aiming at to amplifying the correlation of the form with the object and content with the information of an archaeological collection.
\end{abstract}

Keywords: Museology - Education - Communication. 


\section{Referências bibliográficas}

CACCIARI, C.

1998 Why do we speak Metaphorically?

Reflections in thought and language. In: Katz, A.N.; Cacciari, C.; Gibbs Jr., R.W.;

Turner, M. (Orgs.) Figurative Language and Thought. New York, Oxford University Press: 119-157.

CASTRO, A.

2007 Carta de Roma de Dom Bosco: reflexões. Campo Grande: UCDB.

COSTA, $\mathrm{M}$.

1988 L'estetica della comunicazione: cronologia e documenti. Salerno: Palladio.

CURY, M.X.

2005a Exposição: concepção, montagem e avaliação. São Paulo: Ed. Annablume. 2005.

2005b Comunicação museológica - Uma perspectiva teórica e metodológica de recepção. Tese (Doutoramento em Ciência da Comunicação) - Escola de Comunicações e Artes da Universidade de São Paulo, São Paulo, 366 p.

FABRIS, A.

1995 Sublime Tecnológico de Mario Costa. São Paulo, Experimento.

GASPAR, A.

1993 Museus e centros de ciências: conceituação e proposta de um referencial teórico. Tese (Doutorado em didática) - Faculdade de Educação da Universidade de São Paulo, LAKOFF, G., São Paulo.

1987 Women, Fire and Dangerous Things: what Categories Reveal about the Mind. University of Chicago Press, Chicago.
LAKOFF, G.; TURNER, M.

1989 More than cool reason: a field guide to poetic metaphor. Chicago: The University of Chicago Press.

LORD, B.; LORD, G.D.

1998 Manual de gestión de museos. Barcelona: Ariel Patrimonio Histórico.

POLLIO, H.R.; SMITH, M.K.; POLLIO, M.R.

1990 Figurative language and cognitive psychology. Language and cognitive processes, 5: 141-167.

RIBEIRO, A.C.T. (Org.)

2000 Repensando a Experiência Urbana da América Latina: Questões, Conceitos e Valores. CLACSO - Conselho LatinoAmericano de Ciências Sociais, Buenos Aires.

ROCHA, L.M.G.M.; LOUREIRO, M.L.N.M.; MENDONÇA, D.T.F.; GOUVEIA, M.T.J.; BEDIAGA, B.H.; FORZZA, R.C.

2003 Projeto de Implantação do Museu Botânico do Jardim Botânico do Rio de Janeiro. Relatório do Grupo de Trabalho. Rio de Janeiro.

SILVERSTONE, R.

1994 The medium is the museum: on objects and logics in times and spaces. In: Miles, R.; Zavala, L. (Eds.) Towards the museum of the future: new european perspectives. London, Routledge: 161-176.

SOUZA, M.A.A.

2000 Pedagogia cidadã e tecnologia da informação: Um projeto piloto para a Periferia Sul da Cidade de São Paulo. São Paulo.

TURNER, M.

1996 The Literary mind: The origins of Thought and languages. Oxford: Oxford University Press. 